\title{
Hypertriglyceridemic waist phenotype in primary health care: comparison of two cutoff points
}

This article was published in the following Dove Press journal:

Diabetes, Metabolic Syndrome and Obesity:Targets and Therapy

12 September 2017

Number of times this article has been viewed

\author{
Marina Augusta Dias Braz' \\ Jallyne Nunes Vieira' \\ Flayane Oliveira Gomes' \\ Priscilla Rafaella da Silva' \\ Ohanna Thays de Medeiros \\ Santos' \\ Ilanna Marques Gomes da \\ Rocha $^{2}$ \\ lasmin Matias de Sousa ${ }^{2}$ \\ Ana Paula Trussardi Fayh ${ }^{2}$ \\ 'Faculdade de Ciências da Saúde do \\ Trairi, Universidade Federal do Rio \\ Grande do Norte (UFRN), Santa \\ Cruz, ${ }^{2}$ Department of Nutrition, \\ Centro de Ciências da Saúde, UFRN, \\ Natal, Rio Grande do Norte, Brazil
}

Correspondence: Ana Paula Trussardi Fayh

Departamento de Nutrição, Centro de Ciências da Saúde, Universidade Federal do Rio Grande do Norte, Avenida Senador Salgado Filho, 3000 Bairro, Lagoa Nova, Natal, Rio Grande do Norte, CEP 59078-970, Brazil

Tel +55 843342229 l

Email apfayh@yahoo.com.br
Objective: We aimed to evaluate the prevalence of hypertriglyceridemic waist (HTGW) phenotype among users of primary health care using two different cutoff points used in the literature.

Methods: We evaluated adults and elderly individuals of both sexes who attended the same level of primary health care. HTGW phenotype was determined with measurements of waist circumference (WC) and triglyceride levels and compared using cutoff points proposed by the National Cholesterol Education Program - NCEP/ATP III (WC $\geq 102 \mathrm{~cm}$ for men and $\geq 88 \mathrm{~cm}$ for women; triglyceride levels $\geq 150 \mathrm{mg} / \mathrm{dL}$ for both sexes) and by Lemieux et al (WC $\geq 90 \mathrm{~cm}$ for men and $\geq 85 \mathrm{~cm}$ for women; triglyceride levels $\geq 177 \mathrm{mg} / \mathrm{dL}$ for both).

Results: Within the sample of 437 individuals, $73.7 \%$ was female. The prevalence of HTGW phenotype was high and statistically different with the use of different cutoff points from the literature. The prevalence was higher using the NCEP/ATP III criteria compared to those proposed by Lemieux et al $(36.2 \%$ and $32.5 \%$, respectively, $p<0.05)$. Individuals with the presence of the phenotype also presented alterations in other traditional cardiovascular risk markers.

Conclusion: The HTGW phenotype identified high prevalence of cardiovascular risk in the population, with higher cutoff points from the NCEP/ATP III criteria. The difference in frequency of risk alerts us to the need to establish cutoff points for the Brazilian population.

Keywords: abdominal obesity, cardiovascular disease, dyslipidemia, cardiovascular risk

\section{Introduction}

According to the World Health Organization (WHO), the prevalence of cardiovascular disease (CVD) is increasing in the world, and it is the leading cause of death and disability over the past years. ${ }^{1}$ In this context, it is important to have criteria for the screening of CVD and cardiovascular events for different populations. ${ }^{2}$

In order to make the cardiovascular risk assessment a simple and accessible task at all levels of health care, ${ }^{2}$ Lemieux et $\mathrm{al}^{3}$ proposed a cardiometabolic marker called hypertriglyceridemic waist (HTGW) phenotype. The HTGW phenotype is characterized by the simultaneous presence of increased waist circumference (WC) and high levels of triglycerides, and it is a better predictor for individuals with cardiovascular risk when compared to the components in isolation. ${ }^{4}$ Therefore, the authors propose that the HTGW phenotype may be used as a first marker for tracing and identifying patients with risk of developing metabolic syndrome (MS). ${ }^{5}$ This association is justified by the presence of hyperinsulinemia, high levels of apolipoprotein B and high levels of low-density lipoprotein-cholesterol (LDL-C), due to the levels of visceral adipose tissue. $^{6}$ 
There are two cutoff points available in the literature to identify the presence of HTGW phenotype. The Canadian pioneer group suggested a cutoff point for $\mathrm{men}^{3}$ and, later, a different cutoff point for women, with the only difference being the WC. ${ }^{5}$ The cutoff points of WC and triglyceride levels from this group are different from those proposed by the National Cholesterol Education Program (NCEP-ATP III). ${ }^{7}$ Both cutoff points have been used in studies evaluating the HTGW phenotype. Thus, different prevalence rates can be found in the literature and, sometimes, within the same population, generating confusion among various authors.

In Brazil, there are few studies available about the prevalence of the HTGW phenotype, and no study has proposed a specific cutoff point. Recognizing the lack of studies, the objective of this study was to evaluate the prevalence of the HTGW phenotype in a population of the state of Rio Grande do Norte, Brazil, as well as to compare the results obtained using the two cutoff points available in the literature.

\section{Methods}

An observational study with a cross-sectional design was conducted including individuals of both sexes older than 20 years of age, living in the state of Rio Grande do Norte (Brazil) and who attended a primary health care unit. The participants of the study were selected for convenience, and they were approached at the health service unit which they attended. Only those patients who had biochemical test results, including fasting triglyceride levels, within $<30$ days of the date of assessment were included. The following subjects were excluded: pregnant women, adults and elderly individuals with hepatic diseases, patients with AIDS or malnutrition, or patients who were undergoing renal replacement therapy. All patients signed the form of informed consent in duplicate, and the research project was approved by the Research Ethics Committee of the Federal University of Rio Grande do Norte (protocol 284.437, CAAE 13148313.1.0000.5568).

For the sample size calculation, the HTGW prevalence rate of $10.9 \%$ among the inhabitants of Minas Gerais was considered. ${ }^{2}$ Using an absolute precision of $3 \%$ and a significance level of $5 \%$, it would be necessary to evaluate at least 384 individuals.

Data collection was performed at the primary health care units by properly trained nutrition professionals and academics, in a room reserved for the purpose. First, the patients answered a structured questionnaire with information about their housing, socioeconomic condition and lifestyle. Economic class was evaluated using the Brazilian Association of Research Companies (ABEP) methodology, ${ }^{8}$ which takes into account the number of material goods and monthly-paid employees in the household, the educational level of the main breadwinner, and clustering within the economic classes A1/ $\mathrm{A} 2, \mathrm{~B} 1 / \mathrm{B} 2, \mathrm{C} 1 / \mathrm{C} 2$, D and E, which were later on regrouped as $\mathrm{A} / \mathrm{B}$ [better condition], $\mathrm{C}$ [intermediary condition] and $\mathrm{D} / \mathrm{E}$ [worse condition]). After this interview, the anthropometric nutritional evaluation was performed to characterize the nutritional status and to obtain the WC measurement.

The measurement of body mass was obtained using a properly calibrated mechanical professional balance (Welmy, Sao Paulo, Brazil), supporting up to $150 \mathrm{~kg}$; the individual was asked to remove shoes and heavy clothing and to remain with minimal clothes. To measure the height, the individual remained barefoot in the center of the equipment, erect, with feet together and arms extended along the body, using the measurement technique according to the Frankfurt plan. ${ }^{9}$ To determine the nutritional status, the BMI was calculated, and the nutritional status was ranked according to the cutoff points recommended by WHO. ${ }^{10}$ The nutritional status of people aged $>60$ years was classified according to the cutoff points of Lipschitz. ${ }^{11}$

The WC measurement was performed using inelastic tape at the midpoint between the lower costal margin and the iliac crest. The presence of cardiovascular risk was determined by considering a WC of $102 \mathrm{~cm}$ for men and $88 \mathrm{~cm}$ for women. ${ }^{7}$ The hip circumference ( $\mathrm{HC}$ ) was measured using a measuring tape positioned at the point of greatest circumference of the gluteal region. The waist-to-hip ratio (WHR) was calculated by dividing the $\mathrm{WC}$ by the $\mathrm{HC}$, and the cutoff points used were those established by the $\mathrm{WHO},{ }^{12}$ where the values of WHR $>1$ and WHR $>0.85$ represent risk of developing CVD in men and women, respectively.

The waist-to-height ratio was calculated by dividing the WC (in centimeters) by the height (in centimeters); the cutoff point adopted for abdominal obesity was $0.53 .{ }^{13}$ The sagittal abdominal diameter (SAD) was measured with the mobile rod of an anthropometer having subdivisions of $0.1 \mathrm{~cm}$. During the evaluation, the volunteer remained lying on a firm-surface examination table in the supine position with knees flexed. The measurement was taken at the umbilical level. ${ }^{14}$ For females and males, the cutoff points were 19.3 and $20.5 \mathrm{~cm}$, respectively. ${ }^{15}$

The results of the biochemical tests for the lipid profile (total cholesterol, LDL-C, high-density lipoproteincholesterol [HDL-C] and triglycerides) and glycemia were collected from the medical records or provided by the patients. The results for the blood pressure (BP) were also collected from the medical records. The cutoff point to 
identify changes was $\mathrm{BP} \geq 140 / 90 \mathrm{mmHg}$, established by the Brazilian Hypertension Guideline. ${ }^{16}$

The HTGW prevalence was evaluated through two cutoff points available in the literature: 1 ) that proposed by Lemieux et al, ${ }^{3,5}$ which considers the HTGW phenotype to be present when the triglyceride levels are $\geq 177 \mathrm{mg} / \mathrm{dL}$ and $\mathrm{WC} \geq 90 \mathrm{~cm}$ in men, and $\mathrm{WC} \geq 85 \mathrm{~cm}$ for women; and 2) that proposed by the NCEP-ATP III, which establishes an increased risk of CVDs for measurements of $\mathrm{WC} \geq 102 \mathrm{~cm}$ for men and $\geq 88 \mathrm{~cm}$ for women, and triglyceride levels $\geq 150 \mathrm{mg} / \mathrm{dL}$ for both sexes. $^{7}$

Statistical analyses were performed using SPSS software (version 22.0; IBM Corporation, Armonk, NY, USA). The normality of the data was tested with the Shapiro-Wilk test. Descriptive statistics were used to characterize the sample, with measures of central tendency, dispersion and frequencies. The chi-square test was used to compare the prevalences of the HTGW phenotype, and Cohen's kappa was used as a measure of agreement between the cutoff points. Comparison of the quantitative variables between individuals with or without the HTGW phenotype was performed with independent $t$-test or the Mann-Whitney $U$-test for parametric and nonparametric variables, respectively. The significance level adopted for all analyses was $p \leq 0.05$.

\section{Results}

A total of 437 individuals of both sexes ( $73.7 \%$ female), with a mean age of $48.4 \pm 15.9$ years, ranging from 20 years to 78 years, were evaluated. Table 1 shows the characteristics of the sample, demonstrating that the users were mostly married, nonsmokers and sedentary. No statistically significant association was observed between the sociodemographic data and the presence of the HTGW phenotype.

Table 2 presents data on the frequency of the HTGW phenotype, agreement between cutoff points and comparison of the prevalence of the phenotype between the sexes, with the different cutoff points. Significant differences between the sexes were observed only when the cutoff points of NCEP-ATP III $^{7}$ were used. The frequency of the HTGW phenotype was elevated at both cutoff points, with a statistically significant difference $(p<0.01)$ between them. A higher prevalence $(36.2 \%)$ was observed on using the cutoff point suggested by NCEP-ATP III $^{7}$ when compared to the cutoff points of Lemieux et al $(32.5 \%))^{3,5}$ The agreement between the cutoff points showed that, although the prevalence of the HTGW phenotype was different, agreement was good (kappa $=0.756 ; \mathrm{SE}=0.03$ ).
Table I Sociodemographic description of the sample $(n=437)$

\begin{tabular}{lll}
\hline Characteristics & Number of patients & Percentage \\
\hline Profession & & \\
Houseworker & 69 & 15.8 \\
Farmer & 47 & 10.8 \\
Retired & 93 & 21.3 \\
Teacher & 11 & 2.5 \\
Housekeeper & 19 & 4.3 \\
Autonomous & 37 & 8.5 \\
Other & 155 & 35.5 \\
Marital status & & \\
Single & 118 & 27 \\
Married & 275 & 62.9 \\
Widower & 26 & 5.9 \\
Divorced & 18 & 4.1 \\
Economic class & & \\
A/B & 0 & 0 \\
C & 198 & 45.3 \\
D/E & 239 & 54.7 \\
Smoker & & \\
Yes & 67 & 15.6 \\
No & 312 & 71.6 \\
Former smoker & 57 & 13 \\
Active physically & & \\
Yes & 141 & 31.3 \\
No & 296 & 67.7 \\
Alcohol consumption & & 21.1 \\
Never & 190 & 24.7 \\
Rarely & 47 & \\
Once or twice weekly & 92 & \\
Daily & 108 & \\
\hline Not This & & \\
\hline
\end{tabular}

Note: ${ }^{\text {TThis }}$ definition is based, overall, on the households gross monthly income: Class A, above Brazilian Real (BRL) 10.200; Class B, above BRL 5. 100; Class C, above BRL 2.040; Class D, above BRL 1.020; Class E, below BRL I.020.

Tables 3 and 4 present comparisons between metabolic, cardiovascular and anthropometric variables among individuals with the presence or absence of the HTGW phenotype. In general, for both cutoff points, it is observed that the phenotype is present in individuals with higher age, worse lipid profile, higher glycemia level, overweight and excessive abdominal fat, reinforcing its usefulness to track people with high cardiovascular risk.

\section{Discussion}

The HTGW phenotype stands out because of its high concordance with MS in predicting the risk of developing metabolic diseases ${ }^{17}$ in a simpler way, being easy to apply and inexpensive as well as the involvement of only two parameters. For the diagnosis of MS, at least three of five proposed criteria are needed. ${ }^{18}$ Although simple, it remains little known and is rarely used by health professionals in routine patient evaluation. ${ }^{19}$

The characteristics of the sample in the present study show the main profile found in basic health care units in 
Table 2 Differences between sexes, frequency of the HTGW according to comparative classifications and agreement between cutoff points

\begin{tabular}{|c|c|c|c|c|c|c|}
\hline \multirow[t]{2}{*}{ Classifications } & \multicolumn{2}{|l|}{ Sex } & \multirow[t]{2}{*}{ Total } & \multirow[t]{2}{*}{$p$-value ${ }^{\text {a }}$} & \multirow[t]{2}{*}{$p$-value ${ }^{b}$} & \multirow[t]{2}{*}{$P$-value ${ }^{c}$} \\
\hline & Male & Female & & & & \\
\hline \multicolumn{7}{|l|}{ HTGW/NCEP } \\
\hline Presence & 33 (28.7\%) & 125 (38.8\%) & I 58 (36.2\%) & 0.05 & $<0.01$ & $<0.01$ \\
\hline Absence & 82 (7I.3\%) & 197 (6I.2\%) & $279(63.8 \%)$ & & & \\
\hline Total & II5 (I00\%) & 322 (100\%) & 437 (100\%) & & & \\
\hline \multicolumn{7}{|c|}{ HTGW/Lemieux } \\
\hline Presence & 41 (35.7\%) & 101 (31.4\%) & 142 (32.5\%) & 0.4 & - & - \\
\hline Absence & 74 (64.3\%) & 221 (68.6\%) & 295 (67.5\%) & & & \\
\hline Total & II 5 (100\%) & $322(100 \%)$ & $437(100 \%)$ & & & \\
\hline
\end{tabular}

Notes: ${ }^{a} p$-value for chi-square test between the sexes. ${ }^{b} p$-value for chi-square test between cutoff points. ' $p$-value for Cohen's kappa between cutoff points. HTGW/ NCEP, HTGW according to references of NCEP7 for waist circumference and triglycerides. HTGW/Lemieux, HTGW according to references of Lemieux et al ${ }^{3,5}$ for waist circumference and triglycerides.

Abbreviations: HTGW, hypertriglyceridemic waist; NCEP, National Cholesterol Education Program.

Table 3 Characteristics of the sample according to the presence or absence of HTGW ${ }^{\text {a }}$

\begin{tabular}{|c|c|c|c|}
\hline Variables & Presence of HTGW & Absence of HTGW & $p$-value \\
\hline Age, years $(n=437)$ & $51.03 \pm 14.73$ & $47.2 \pm 16.29$ & $<0.01^{\mathrm{b}}$ \\
\hline Triglycerides, mg/dL ( $n=437)$ & $281.43 \pm 121.20$ & $126 \pm 60.80$ & $<0.01^{c}$ \\
\hline Cholesterol, mg/dL $(n=433)$ & $233.32 \pm 51.03$ & $188.89 \pm 40.62$ & $<0.0 I^{b}$ \\
\hline HDL-cholesterol, mg/dL $(n=365)$ & $45.16 \pm 10.76$ & $50.93 \pm 14.52$ & $<0.01^{\mathrm{b}}$ \\
\hline LDL-cholesterol, mg/dL ( $\mathrm{n}=344)$ & $|36.90 \pm 4| .93$ & $113.17 \pm 37.55$ & $<0.01^{b}$ \\
\hline Glucose, $\mathrm{mg} / \mathrm{dL}(\mathrm{n}=425)$ & $118.20 \pm 52.70$ & $95.4 \pm 32.80$ & $<0.01^{b}$ \\
\hline $\mathrm{SBP}, \mathrm{mmHg}(\mathrm{n}=393)$ & $127.26 \pm 14.46$ & $\mid 23.01 \pm 18.74$ & $<0.01^{\mathrm{b}}$ \\
\hline $\mathrm{DBP}, \mathrm{mmHg}(\mathrm{n}=393)$ & $76.84 \pm \mid 7.01$ & $77.90 \pm 14.35$ & $<0.01^{b}$ \\
\hline $\mathrm{BMI}, \mathrm{kg} / \mathrm{m}^{2}(\mathrm{n}=437)$ & $30.05 \pm 4.92$ & $28.05 \pm 6.48$ & $<0.01^{\mathrm{b}}$ \\
\hline Waist circumference, $\mathrm{cm}(\mathrm{n}=437)$ & $96.08 \pm 12.65$ & $88.90 \pm 15.20$ & $<0.01^{b}$ \\
\hline Hip circumference, $c m(n=3 \mid 5)$ & $104.58 \pm 9.16$ & $101.48 \pm 10.77$ & $<0.01^{b}$ \\
\hline WHR $(n=3 \mid 5)$ & $0.89 \pm 0.83$ & $0.84 \pm 0.09$ & $<0.01^{\mathrm{b}}$ \\
\hline Waist-to-height ratio $(n=437)$ & $0.60 \pm 0.07$ & $0.55 \pm 0.10$ & $<0.01^{c}$ \\
\hline $\mathrm{SAD}, \mathrm{cm}(\mathrm{n}=209)$ & $21.67 \pm 3.58$ & $20.36 \pm 3.90$ & $<0.01^{b}$ \\
\hline
\end{tabular}

Notes: a As proposed by Lemieux et al (2000/2007). ${ }^{3,5}$ b $p$-value obtained using the chi-square test; ${ }^{c} p$-value obtained using independent $t$-test.

Abbreviations: BMI, body mass index; DBP, diastolic blood pressure; HDL, high-density lipoprotein; HTGW, hypertriglyceridemic waist; LDL, low-density lipoprotein; SAD, sagittal abdominal diameter; SBP, systolic blood pressure; WHR, waist-to-hip ratio.

Table 4 Characteristics of the sample according to the presence or absence of HTGWa

\begin{tabular}{|c|c|c|c|}
\hline Variables & Presence of HTGW & Absence of HTGW & $p$-value \\
\hline Age, years $(n=437)$ & $51.01 \pm 14.99$ & $46.99 \pm 16.22$ & $<0.0 \mathrm{I}^{\mathrm{b}}$ \\
\hline Triglycerides, mg/dL $(n=437)$ & $250.26 \pm 116.27$ & $135.28 \pm 84.87$ & $<0.0 I^{c}$ \\
\hline Cholesterol, mg/dL $(n=433)$ & $223.94 \pm 51.66$ & $191.60 \pm 43.10$ & $<0.0 I^{b}$ \\
\hline HDL-cholesterol, mg/dL $(n=365)$ & $45.46 \pm 10.80$ & $51.09 \pm 14.68$ & $<0.01^{b}$ \\
\hline LDL-cholesterol, mg/dL ( $\mathrm{n=344)}$ & $133.14 \pm 42.48$ & $1|3.7| \pm 37.65$ & $<0.0 I^{b}$ \\
\hline Glucose, $\mathrm{mg} / \mathrm{dL}(\mathrm{n}=425)$ & $116 \pm 50.50$ & $100.06 \pm 39.63$ & $<0.0 I^{b}$ \\
\hline SBP, $\mathrm{mmHg}(\mathrm{n}=393)$ & $125.68 \pm 13.92$ & $|23.66 \pm| 9.4 \mid$ & $<0.0 \mathrm{I}^{\mathrm{b}}$ \\
\hline DBP, $m m H g(n=393)$ & $77.77 \pm 16.05$ & $77.4| \pm| 4.8 \mid$ & $<0.0 I^{b}$ \\
\hline BMI, $\mathrm{kg} / \mathrm{m}^{2}(\mathrm{n}=437)$ & $31.05 \pm 5.18$ & $27.36 \pm 6.16$ & $<0.0 I^{b}$ \\
\hline Waist circumference, $\mathrm{cm}(\mathrm{n}=437)$ & $97.92 \pm 12.66$ & $87.44 \pm 14.59$ & $<0.0 I^{b}$ \\
\hline Hip circumference, $\mathrm{cm}(\mathrm{n}=3 \mid 5)$ & $106.44 \pm 9.20$ & $100.16 \pm 10.26$ & $<0.0 I^{b}$ \\
\hline WHR $(n=3 \mid 5)$ & $0.89 \pm 0.08$ & $0.84 \pm 0.09$ & $<0.0 I^{b}$ \\
\hline Waist-to-height ratio $(n=437)$ & $0.6 I \pm 0.07$ & $0.54 \pm 0.09$ & $<0.0 \mathrm{I}^{\mathrm{c}}$ \\
\hline SAD, cm $(n=209)$ & $22.24 \pm 3.67$ & $20.03 \pm 3.71$ & $<0.0 I^{b}$ \\
\hline
\end{tabular}

Notes: ${ }^{a}$ Based on NCEP criteria (2000). ${ }^{7 b} p$-value obtained using the chi-square test; ${ }^{c} p$-value obtained using independent $t$-test.

Abbreviations: BMI, body mass index; DBP, diastolic blood pressure; HDL, high-density lipoprotein; HTGW, hypertriglyceridemic waist; LDL, low-density lipoprotein; NCEP, National Cholesterol Education Program; SAD, sagittal abdominal diameter; SBP, systolic blood pressure; WHR, waist-to-hip ratio. 
Brazil: the majority were female, married and sedentary, with no usual alcohol consumption and belonging to the less-favored socioeconomic class. These characteristics were also found in other studies in the country, which indicate that women are the main users of basic health care units..$^{20,21}$ The predominance of the population in the less-favored economic classes, as observed by Haack et al, ${ }^{21}$ can be explained by the data collection site, which is a public health service. The low frequency of smokers, physically active persons or frequent consumers of alcohol explains the fact that these characteristics are not associated with the HTGW phenotype.

Our results showed differences in the presence of the phenotype according to the cutoff points, as well as a good agreement between the cutoff points, with the highest frequency observed when the cutoff point suggested by the NCEP/ATP III $^{7}$ was used. Until now, there have been few studies to report appropriate cutoffs of HTGW among Brazilian adults or the association between HTGW and risk for chronic diseases. Unfortunately, in the present study, it was not possible to predict the best cutoff point for the study population because we did not have access to the medical diagnoses of diabetes or hypertension (many subjects were not sure if they had these diseases). Recognizing that the Brazilian population is characterized by different ethnicities and does not have a specific cutoff point for indicators of abdominal obesity, we suggest the use of NCEP/ATP III cutoff point because it can recognize more patients at risk and, using this, we anticipate the prevention of CVDs.

In addition to the increased incapacitation and mortality associated with overweight and obesity, there is numerous evidence associating visceral fat accumulation with increased cardiovascular risk of metabolic origin. Thus, visceral adipose tissue becomes a major cardiovascular risk factor correlating well with proatherogenic, prodiabetogenic, prothrombogenic and proinflammatory status. ${ }^{22}$ It is also established that the accumulation of abdominal fat may be the result of an increase in visceral or subcutaneous adipose tissue and is an indicator for the prediction of cardiovascular risk. ${ }^{15}$ Thus, it is proven that the HTGW phenotype is a useful marker for the identification of cardiovascular risk by recognizing the association between WC and triglyceride levels.

Among the few available studies on the prevalence of the HTGW phenotype in Brazil, a study conducted by Guattini et $\mathrm{al}^{4}$ in the city of Porto Alegre, Rio Grande do Sul, with individuals aged $\geq 40$ years, showed a $48.9 \%$ prevalence of individuals with the phenotype and $55.6 \%$ of individuals with increased WC. The cutoff point adopted for that study was suggested by Brazilian guidelines $(\mathrm{WC} \geq 94 \mathrm{~cm}$ for men and $\geq 80 \mathrm{~cm}$ for women and $\mathrm{TG} \geq 150 \mathrm{mg} / \mathrm{dL}$ for both sexes). ${ }^{23}$ Another study carried out by Cabral et $\mathrm{al}^{20}$ found a prevalence of $33 \%$ in hypertensive women $\geq 50$ years old in the city of São Luís, Maranhão, using the cutoff points of the NCEP. ${ }^{7}$ However, in the southern region of Brazil, smaller values were found in a study conducted with young adults between 22 and 23 years of age, with a prevalence of the HTGW phenotype of $5.9 \%$ in men and $4.5 \%$ in women. ${ }^{21}$ The cutoff point adopted in that study was that proposed by Lemieux et al. ${ }^{3,5}$

Mendes and Melendez ${ }^{2}$ also performed a population-based study in Brazil with the purpose of describing the HTGW phenotype. A total of 506 individuals, 42.13 \pm 15.94 years old, were evaluated in the city of Belo Horizonte, Minas Gerais, and a $11.1 \%$ prevalence of individuals with HTGW was found. The cutoff point adopted in that study was calculated from the receiver operating characteristic (ROC) curve obtained with the values found in the sample, wherein the following cutoff values were obtained: $\mathrm{WC} \geq 85.30 \mathrm{~cm}$ and triglyceride levels $\geq 114.8 \mathrm{mg} / \mathrm{dL}$ for men; and $\mathrm{WC}$ $\geq 87.50 \mathrm{~cm}$ and triglyceride levels $\geq 124.5 \mathrm{mg} / \mathrm{dL}$ for women. Although the proposed cutoff point presented lower values, the prevalence of HGTW was lower than that found in the present study, which used cutoff points with higher values commonly found in the literature. This can be explained by the fact that the population in that study was younger and because it was evaluated at random. Our study was carried out with older individuals who seek primary health care, which thus is characterized as a higher-risk group among the public. The low value of the proposed cutoff points were unsuitable for use in the present study because it would be an underestimation of the result found for the phenotype.

In other studies performed in populations from different countries, different prevalence rates of HTGW were observed. In Spain, in a study carried out by Cortés et al, ${ }^{17}$ it was possible to evaluate the presence of the phenotype from two cutoff points: NCEP ATP III and the International Diabetes Federation (IDF) (WC $\geq 94 \mathrm{~cm}$ and $\geq 80 \mathrm{~cm}$ for men and women, respectively; and triglyceride levels $\geq 150 \mathrm{mg}$ for both sexes). ${ }^{24}$ The study observed a prevalence of $49.2 \%$ of individuals with HTGW using the first cutoff point and a prevalence of $79.7 \%$ using the second. This difference can be explained by the fact that the cutoff point suggested by the IDF presents lower values for WC. In another study, also carried out in Spain and evaluating 2270 individuals between 18 and 80 years old, a variation of $14.5 \%$ in individuals with the presence of the HTGW phenotype was observed through the cutoff point suggested by NCEP-ATP III. ${ }^{25}$ 
Amini et al ${ }^{26}$ evaluated 1323 Iranians with a clinical history of type II diabetes and age between 30 and 55 years, and they found a prevalence of HTGW of $23.6 \%$ among women and $9.6 \%$ among men using the cutoff point of NCEP-ATP III. Gasevic et $\mathrm{al}^{27}$ evaluated 809 adults of different ethnicities living in Canada and aged 30-65 years old, and detected a prevalence of $22.3 \%$ in men and $17 \%$ in women, using the cutoff point of Lemieux et al. ${ }^{3,5}$ In Malaysia, Zainuddin et $\mathrm{al}^{28}$ evaluated 298 people aged 18-70 years using two different cutoffs for the HTGW phenotype: IDF ${ }^{24}$ and NCEP/ATPIII. ${ }^{7}$ Similar to the results of the present study, those authors found good concordance of these cutoff points, and the prevalence of the HTGW phenotype was $19.7 \%$ (with the IDF cutoff point). Thus, we can see that there is no consensus among authors about the best cutoff point for identifying the HTGW phenotype in different countries.

The prevalence of MS in adults identified with the HTGW phenotype is high. A study observed that $97.5 \%$ of individuals with the phenotype also had MS. ${ }^{28}$ Thus, the correlation in the diagnosis of cardiovascular risk among these evaluation criteria can be considered high. Similar results were observed in a study of 254 women undergoing angiography to verify coronary artery disease. ${ }^{29}$ The cutoff point used was the one proposed by NCEP-ATP III, ${ }^{7}$ in which a higher cardiovascular risk was detected among participants with MS, the HTGW phenotype and a high Framingham risk score. ${ }^{29}$

The present study also observed that individuals with the HTGW phenotype show different changes in cardiometabolic markers, regardless of the cutoff point. People who do not have the phenotype have fewer changes in these markers as well as in the factors considered protective against the development of CVDs, such as higher HDL-C. Similar results were found by Rocha et $\mathrm{al}^{30}$ in a study carried out in Viçosa, Minas Gerais, evaluating 976 individuals aged 20-59 years, wherein the authors identified that the highest averages for all cardiometabolic risk factors analyzed were observed in the HTGW phenotype group and lower values of HDL were also found only in this group.

One limitation of the present study was that a cardiovascular event was not adopted to test the prediction of the phenotype. Studies in the literature have investigated the association of the phenotype with subclinical atherosclerosis, ${ }^{27}$ cholesterol and C-reactive protein ${ }^{23}$ as well as overweight and glycemia levels. ${ }^{22}$ It is suggested that future investigations study the frequency of the phenotype and its association with events associated with metabolic risk in order to improve the knowledge about these interrelations and to potentiate the clinical use of this indicator.

\section{Conclusion}

There was a high frequency of the HTGW phenotype in the population, regardless of the cutoff point used, as well as a high frequency of cardiovascular risk factors, especially in participants with HTGW. The frequency was higher when using the cutoff points suggested by NCEP-ATPIII. Thus, it is reaffirmed that the HTGW phenotype is a simple and inexpensive marker that should be used in clinical practice because, through this research and other reports available in the literature, it was observed that there is a high prevalence of the HTGW phenotype in the population. Further prospective investigations are necessary to understand the predictive usefulness of the HTGW phenotype in a population attended to in a primary health care setting, to screen for patients at a high risk for diabetes and other cardiometabolic diseases.

\section{Author contributions}

All authors contributed toward data analysis, drafting and critically revising the paper and agree to be accountable for all aspects of the work.

\section{Disclosure}

The authors report no conflicts of interest in this work.

\section{References}

1. World Health Organization. World Health Statistics. A Wealth of Information on Global Public Health. 2016. Available from: http://apps. who.int/iris/bitstream/10665/112739/1/WHO_HIS_HSI_14.1_eng. pdf?ua=1. Accessed April 24, 2016.

2. Mendes F, Melendez J. Cintura hipertrigliceridêmica e sua associação com fatores de risco metabólicos [Hypertrigliceridemic Waist and Associations with Metabolic Risk Factors] [dissertation]. Belo Horizonte: Federal University of Minas Gerais; 2009. Portuguese.

3. Lemieux I, Pascot A, Couillard C, et al. Hypertriglyceridemic waist: a marker of the atherogenic metabolic triad (hyperinsulinemia, hyperapolipoprotein B, small, dense LDL) in men? Circulation. 2000;102(2): 179-184.

4. Guattini V, Piovesan C, Wittke E, Marcadenti A. Hypertriglyceridemic waist (EWET), glycidic and lipid profile in patients with newly diagnosed heart attack. Nutr Hosp. 2015;32(3):1004-1008.

5. Lemieux I, Poirier P, Bergeron J, et al. Hypertriglyceridemic waist: a useful screening phenotype in preventive cardiology? Can J Cardiol. 2007;23(suppl B):23B-31B.

6. Cunha O, Carneiro R, Eickemberg M, Barreto M, Barbosa R. Hypertriglyceridemic waist phenotype: association with metabolic disorders and visceral fat in adults. Nutr Hosp. 2014;30(1):25-31.

7. Expert Panel on Detection, Evaluation and Treatment of High Blood Cholesterol in Adults. Executive summary of the third report of the National Cholesterol Education Program (NCEP) expert panel on detection, evaluation, and treatment of high blood cholesterol in adults (adult treatment panel III). JAMA. 2001;285(19):2486-2497.

8. Brazil Economic Classification Criterion [database on the Internet]. 2009. Available from: http://www.abep.org/criterio-brasil.

9. Sistema de Vigilância Alimentar e Nutricional - SISVAN. Orientações para a coleta e análise de dados antropométricos em serviços de saúde [Orientations to Data Collection and Analysis of Anthropometric Data in Health Services]. Brasília: Ministério da Saúde; 2007:76. 
10. World Health Organization. Physical Status: The Use and Interpretation of Anthropometry. Geneva: World Health Organization; 1995:854.

11. Lipschitz DA. Screening for nutritional status in the elderly. Prim Care. 1994;21(1):55-67.

12. World Health Organization. Obesity: Preventing and Managing the Global Epidemic - Report of a WHO Consultation on Obesity. Geneva: World Health Organization; 1998:252.

13. Hauan DR, Pitanga FJ, Lessa I. Razão Cintura/Estatura comparado a outros indicadores antropométricos de obesidade como preditor de risco coronariano elevado. [Waist/height ratio compared to other antrophometric indicators of obesity as a predictor of high coronary risk]. Rev Assoc Med Bras. 2009;55(6):705-711. Portuguese.

14. Ohrvall M, Berglund L, Vessby B. Sagittal abdominal diameter compared with other anthropometric measurements in relation to cardiovascular risk. Int J Obes Relat Metab Disord. 2000;24(4):497-501.

15. Sampaio LR, Simoes EJ, Assis AM, Ramos LR. Validade e confiabilidade do diâmetro abdominal sagital enquanto preditor de gordura abdominal visceral [Validity and reliability of sagittal abdominal diameter as a predictor of visceral abdominal fat]. Arq Bras Endocrinol Metab. 2007;51(6):980-986. Portuguese.

16. Malachias MVB 7th. Brazilian guideline of arterial hypertension. Arq Bras Cardiol. 2016;107(3):1-113. Portuguese.

17. Cortés JM, Morato TM, Toro R, et al. Sindrome metabólico en pacientes com fenotipo clínico de "cintura hipertrigliceridémica" [Metabolic syndrome in patients with hypertriglyceridemic waist phenotype]. Nutr Hosp. 2015;32(3):1145-1152. Portuguese.

18. Sociedade Brasileira de Cardiologia. I Diretriz Brasileira de Diagnóstico e Tratamento da Síndrome Metabólica [I Brazilian guideline for diagnosis and treatment of metabolic syndrome]. Arq Bras Cardiol. 2005;84(suppl 1);1-28. Portuguese.

19. Gupta M, Singh N, Tsiqoulis M, et al. Perceptions of Canadian primary care physicians towards cardiovascular risk assessment and lipid management. Can J Cardiol. 2012;28(1):14-19.

20. Cabral NAL, Ribeiro VS, França AKTC, et al. Cintura hipertrigliceridêmica e risco cardiometabólico em mulheres hipertensas [Hypertriglyceridemic waist and cardiometabolic risk in hypertensive women]. Rev Assoc Med Bras. 2012;58(5):568-573. Portuguese.
21. Haack RL, Horta BL, Gigante DP, Barros FC, Oliveira I, Silveira VM. The hypertriglyceridemic waist phenotype in Young adults from the Southern Region of Brazil. Cad Saude Publica. 2013;29(5): 999-1007.

22. Wakabayashi I, Daimon T. Age-dependent decline of association between obesity and hyperglycemia in men and women. Diabetes Care. 2012;35(1):175-177.

23. Sociedade Brasileira De Cardiologia. IV Diretriz Brasileira sobre dislipidemias e prevenção da aterosclerose [IV Brazilian Guideline on dyslipidemia and prevention of atherosclerosis]. Departamento de Aterosclerose da Sociedade Brasileira de Cardiologia. Arq Bras Cardiol. 2007;88(suppl 1):1-18. Portuguese.

24. International Diabetes Federation [homepage on the Internet]. The IDF Consensus Worldwide Definition of Metabolic Syndrome. 2017. Available from: http://www.idf.org. Accessed March 12, 2017.

25. Gomez HR, Bernal LMR, Villalobos A, et al. Hypertriglyceridemic waist: an alternative to the metabolic syndrome? Results of the IMAP study (multidisciplinary intervention in primary care). Int JObes. 2011;35(2): 292-299.

26. Amini M, Esmaillzadeh A, Sadeghi M, Mehvarifar N, Amini M, Zare $\mathrm{M}$. The association of hypertriglyceridemic waist phenotype with type 2 diabetes mellitus among individuals with first relative history of diabetes. J Res Med Sci. 2011;16(2):64-156.

27. Gasevic D, Carlsson AC, Lesser IA, Mancini JGB, Lear SA. The association between "hypertriglyceridemic waist" and sub-clinical atherosclerosis in a multiethnic population: a cross-sectional study. Lipids Health Dis. 2014;13:38.

28. Zainuddin LRM, Isa N, Muda WMW, Mohamed HJ. The prevalence of metabolic syndrome according to various definitions and hypertriglyceridemic waist in Malaysian adults. Int J Prev Med. 2011;2(4): 229-237.

29. Blackburn P, Lemieux I, Lamarche B, et al. Hypertriglyceridemic waist: a simple clinical phenotype associated with coronary artery disease in women. Metabolism. 2012;61(1):56-64.

30. Rocha ALC, Pereira PF, Pessoa MC, et al. Hypertriglyceridemic waist phenotype and cardiometabolic alterations in Brazilian adults. Nutr Hosp. 2015;32(3):1099-1106.
Diabetes, Metabolic Syndrome and Obesity: Targets and Therapy is an international, peer-reviewed open-access journal committed to the rapid publication of the latest laboratory and clinical findings in the fields of diabetes, metabolic syndrome and obesity research. Original research, review, case reports, hypothesis formation, expert opinion and commentaries are all considered for publication. The manuscript management system is completely online and includes a very quick and fair peer-review system, which is all easy to use. Visit http://www.dovepress.com/testimonials.php to read real quotes from published authors. 